\title{
Reliability of SnAgCuFe Solder Joints in WLCSP30 Device
}

\author{
Zhang Liang ${ }^{1,2}$, Guo Yonghuan ${ }^{2}$, Sun Lei ${ }^{1}$, He Chengwen ${ }^{1}$ \\ ${ }^{1}$ Jiangsu Normal University, Xuzhou 221116, China; ${ }^{2}$ University of California at Los Angeles, Los Angeles, CA 90095, USA
}

\begin{abstract}
Anand constitutive model of $\mathrm{SnAgCuFe}$ solder joints was studied, and 9 parameters were determined based on tensile testing. And the model was incorporated in finite element code for analyzing the stress-strain response of $\mathrm{SnAgCuFe}$ solder joints in WLCSP30 device. The results indicate that the maximum stress concentrates on the top surface of corner solder joints, and the stress-strain of $\mathrm{SnAgCuFe}$ solder joints is lower than that of $\mathrm{SnAgCu}$ solder joints. Based on the fatigue life model, the addition of $\mathrm{Fe}$ can enhance the fatigue life of $\mathrm{SnAgCu}$ solder joints. Therefore, the $\mathrm{SnAgCuFe}$ solders can replace the traditional $\mathrm{SnPb}$ to be used in electronic packaging.
\end{abstract}

Key words: Anand model; solder joints; stress-strain; fatigue life

Semiconductor industries are striving to find viable alternatives to lead-based solder in order to meet world-wide regulatory requirements (human health and environment) on the restrictions on the use of lead $(\mathrm{Pb} \text { : toxic })^{[1,2]}$. Among these lead-free solders, $\mathrm{SnAgCu}$ solder has been proposed by lots of researchers $^{[3-5]}$ to replace the traditional $\mathrm{SnPb}$ alloys in electronic industry because of its relatively low melting temperature compared to the SnAg binary eutectic alloy, and better solderability and mechanical properties compared with the $\mathrm{SnCu}$ binary eutectic solder. However, there are some drawbacks for the $\mathrm{SnAgCu}$ solders, e.g., brittle phase in the matrix, and lower thermal fatigue behavior.

In order to improve the properties of $\mathrm{SnAgCu}$ solder, an alloying method was used to modify the alloys. The fourth elements can be added into $\mathrm{SnAgCu}$ solder. The rare earth $\mathrm{Ce}$ was selected by L. Zhang ${ }^{[6]}$, and it was observed that $0.03 \% \mathrm{Ce}$ can enhance the fatigue life of $\mathrm{SnAgCu}$ solder joints. K. S. $\mathrm{Kim}^{[7]}$ found that fourth elements (Fe, Ni, Co, Mn, Ti) can refine the microstructures of $\mathrm{SnAgCu}$ solders, and all quaternary bulk alloys exhibited similar or slightly larger tensile strengths. X. Y. $\mathrm{Liu}^{[8]}$ demonstrated that with the addition of Fe particles, the tensile strength and the hardness of $\mathrm{SnAgCu}$ solder joints can be improved significantly. Y. W. Wang $^{[9]}$ proved that minor $\mathrm{Fe}, \mathrm{Co}$ and $\mathrm{Ni}$ can reduce the
$\mathrm{Cu} 3 \mathrm{Sn}$ thickness of $\mathrm{SnAgCu} / \mathrm{Cu}$ solder joints, and the strength was also enhanced. The addition of $\mathrm{Al}$ nanoparticles into $\mathrm{SnAgCu}$ solder joints improved the wettability, mechanical properties, fatigue life of solder joints, refined the microstructures, and inhibited the IMC layer growth ${ }^{[10-12]}$. For the series of new $\mathrm{SnAgCu}$ base lead-free solders, the reliability should be studied before the application in electronic industry.

In the present paper, the reliability of $\mathrm{Sn} 3.8 \mathrm{Ag} 0.7 \mathrm{Cu} 0.8 \mathrm{Fe}$ solder was researched based on finite element simulation. The parameters of $\mathrm{SnAgCuFe}$ solders were determined based on tensile testing, and combing with the finite element code the stress-strain response was analyzed. The fatigue life was computed to analyze the reliability of solder joints.

\section{Determination of Parameters}

For the finite element simulation of solder joints in electronic components, the constitutive mode is needed to represent the nonlinear stress-strain response. Until now, there are many types of constitutive relations based on the creep strain, plastics strain, and von Mises stress. Among these constitutive models, Anand model was proposed to describe the inelastic deformation of lead-free solders, the physical mechanisms such as temperature sensitivity, strain hardening, strain rate sensitivity, strain rate and temperature history effects should be taken into account.

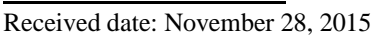

Foundation item: National Natural Science Foundation of China (51475220); Natural Science Foundation of Jiangsu (BK2012144); Natural Science Foundation of the Higher Educations of Jiangsu Province (12KJB460005)

Corresponding author: Zhang Liang, Ph. D., Professor, School of Mechanical and Electrical Engineering, Jiangsu Normal University, Xuzhou 221116, P. R. China, Tel: 0086-516-83403320, E-mail: zhangliang@jsnu.edu.cn 
The following functional form for the flow equation of Anand model was selected to exactly accommodate the strain rate dependence on the stress at constant structure ${ }^{[13]}$ :

$$
\dot{\varepsilon}_{\mathrm{p}}=A \exp \left(-\frac{Q}{R T}\right)\left[\sinh \left(\xi \frac{\sigma}{s}\right)\right]^{1 / m}
$$

where $\dot{\varepsilon}_{\mathrm{p}}$ is the inelastic strain rate, $A$ is the pre-exponential factor, $Q$ is the activation energy, $R$ is the gas constant, $T$ is the absolute temperature, $\xi$ is the multiplier of stress, $\sigma$ is the applied stress, $s$ is a single scalar as an internal variable to represent the averaged isotropic resistance to plastic flow, and $m$ is the strain rate sensitivity of stress.

The evolution equation is represented as

$$
\dot{s}=\left[h_{0}\left|1-\frac{s}{s^{*}}\right|^{a} \operatorname{sign}\left(1-\frac{s}{s^{*}}\right)\right] \dot{\varepsilon}_{\mathrm{p}}
$$

where $a>1$.

$$
s^{*}=\widehat{s}\left[\frac{\dot{\varepsilon}_{\mathrm{p}}}{A} \exp \left(\frac{Q}{R T}\right)\right]^{n}
$$

where $h_{0}$ is the hardening/softening constant, $s^{*}$ is the saturation value of $S, a$ is the strain rate sensitivity of hardening/softening, $\hat{s}$ is the coefficient for the saturation deformation resistance, and $n$ is the strain rate sensitivity for the saturation value of deformation resistance.

Based on the tensile testing, the nine parameters of Anand model can be determined. In our previous work $^{[14]}$, the experimental parameter of uniaxial tensile tests, and the standard calculation procedure were described in detail. Therefore, the experimental procedure can be omitted in this paper. The nine parameters determined based on the fitting of experimental data are shown in Table 1. Moreover the parameters $^{[15]}$ of $\mathrm{SnPb}$ solders are also shown in Table 1, and the data will used for the comparison analysis of finite element simulation. Fig.1 shows the experimental data and Anand data, and good agreement can be seen between experimental data and predicted data using Anand model.

\section{Finite Element Simulation}

A 1/4 symmetry model of the WLCSP 30 device was used to predict the stress-strain response. SOLID186 elements were employed for meshing all the materials except solder joints,

Table 1 Nine parameters of solders

\begin{tabular}{cccc}
\hline Materials parameters & SnAgCuFe & $\mathrm{SnAgCu}$ & $\mathrm{SnPb}$ \\
\hline$A / \mathrm{s}^{-1}$ & 23765 & 24300 & 6220 \\
$Q / R / \mathrm{K}^{-1}$ & 8311 & 8710 & 6526 \\
$\hat{S} / \mathrm{MPa}$ & 59.1 & 65.3 & 36.86 \\
$h_{0} / \mathrm{MPa}$ & 3844.7 & 3541.2 & 60599 \\
$\xi$ & 5.4 & 5.8 & 3.33 \\
$m$ & 0.15 & 0.183 & 0.27 \\
$n$ & 0.0181 & 0.019 & 0.022 \\
$a$ & 2.5 & 1.9 & 1.7811 \\
$s_{0} / \mathrm{MPa}$ & 37.3 & 39.5 & 3.1522 \\
\hline
\end{tabular}

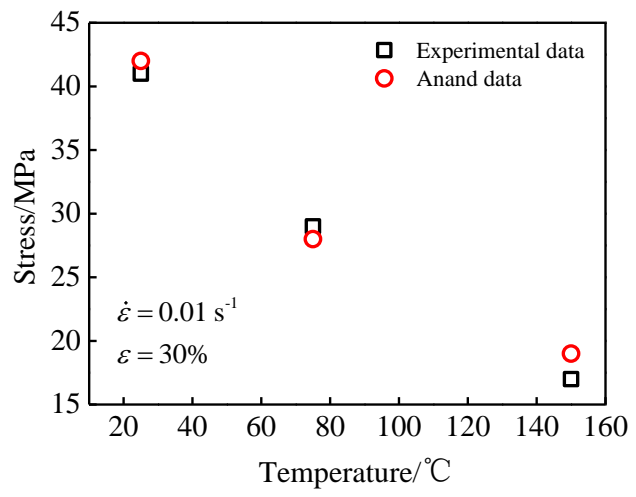

Fig.1 Stress data of solders

and VISCO107 for solder joints. The finite element mode of 1/4 WLCSP device is shown in Fig.2.

According to MIL-STD-883 specification ${ }^{[16]}$, thermal cycle loading was selected to be imposed on the WLCSP30 assembly. It was performed at temperatures ranging from 218 $\mathrm{K}$ to $398 \mathrm{~K}$, with dwell time at all peak temperature $15 \mathrm{~min}$, the rates of descend and ascend temperature $15 \mathrm{~K} / \mathrm{min}$. Ten cycles were used to simulate the stress-strain response of $\mathrm{SnAgCu}$ and $\mathrm{SnAgCuFe}$ solder joints.

Fig.3 shows the Von Mises stress of solder joints in WLCSP30 device. The critical solder joints (most vulnerable to fatigue cracking) of the WLCSP are determined by plotting the contour of the stress. The critical solder joints are in the corner of the array, the largest stress area is the top-surface of the corner solder joints near the chip, and the area is then defined as the key location that is the easiest to be failed under thermal cycles. In Zhao's experiments ${ }^{[17]}$, the fatigue crack path was found in the solder joints and along a thin layer of solder connecting to the chip, which demonstrated that the crack happened in the largest stress area. The stress distribution is not uniform, and there is no essential difference in the stress distribution between the $\mathrm{SnAgCu}$ and $\mathrm{SnAgCuFe}$ solder joints, while only the stress value differs.

Fig.4 plots the Von Mises stress of $\mathrm{SnAgCu}$ and $\mathrm{SnAgCuFe}$ solder joints in WLCSP30 devices. It is evident that the level of stress in the $\mathrm{SnAgCuFe}$ solder joints is lower than that of

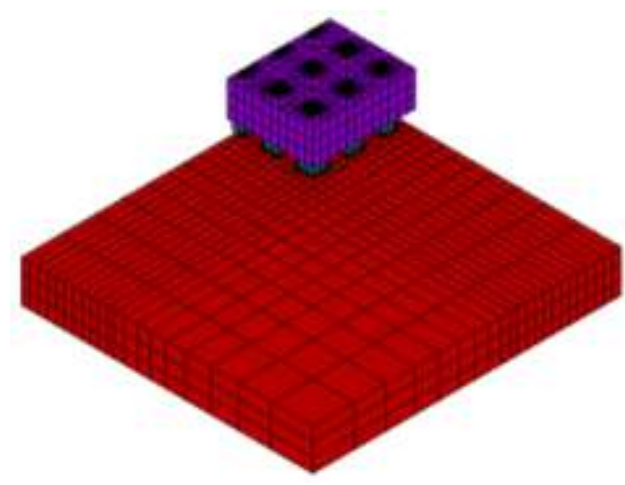

Fig.2 Finite element model of WLCSP30 


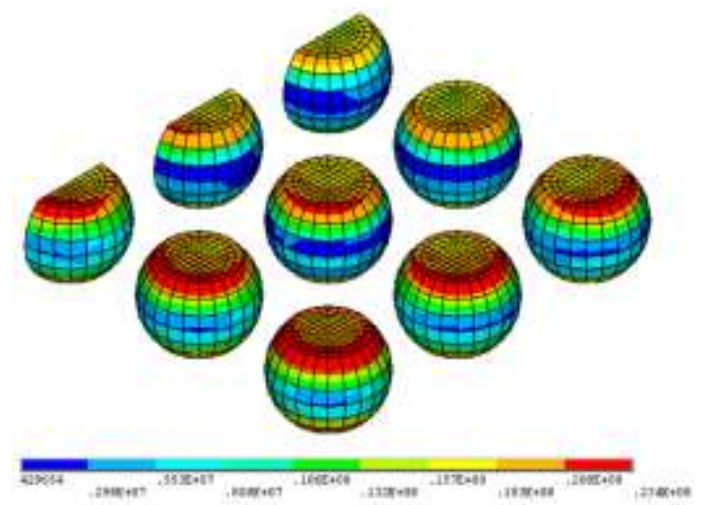

Fig.3 Von Mises stress of solder joints

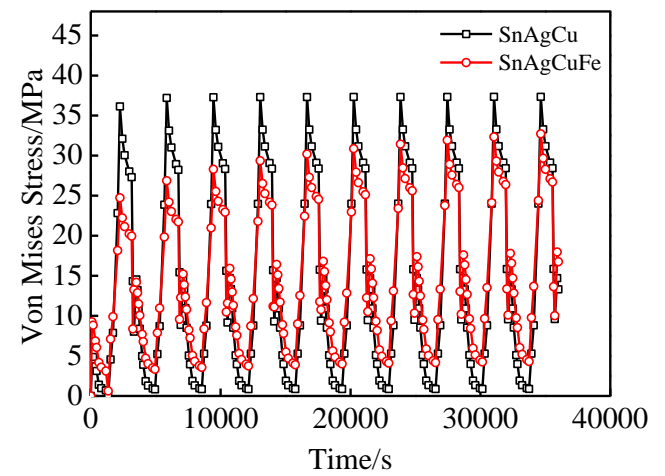

Fig.4 Von Mises stress of $\mathrm{SnAgCu} / \mathrm{SnAgCuFe}$

the $\mathrm{SnAgCu}$ solder joint during the whole process. And the relaxation phenomena and hysteresis performance during the ramp-up of temperature can be observed in all the solder joints. The similar phenomena can be found in $\mathrm{SnAgCu}, \mathrm{SnAg}$ and $\mathrm{SnPb}$ solder joints of PLCC devices ${ }^{[18]}$.

For the finite element simulation, it is important to study response for multiple cycles until the stress-strain become stable. Fig. 5 shows the von Mises strain curves of $\mathrm{SnAgCu}$ and $\mathrm{SnAgCuFe}$ solder joints in WLCSP devices during ten cycles. It can be found that the von Mises strain is quite stabilized after the second cycle for the two kinds of solder joints, both increase steadily for the ten cycles, and the von

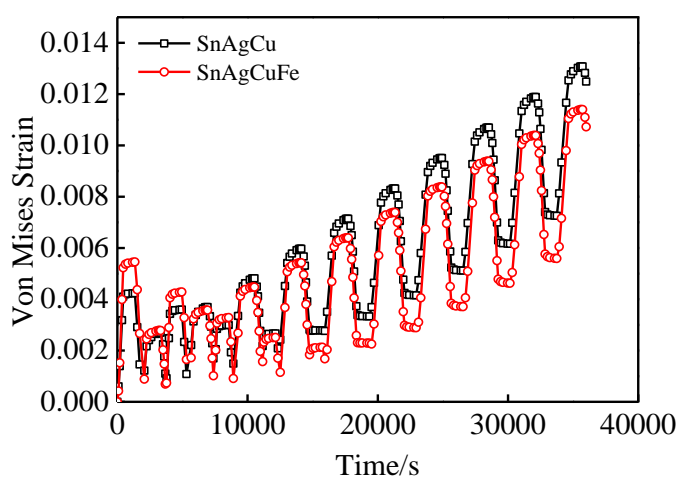

Fig.5 Von Mises strain of $\mathrm{SnAgCu} / \mathrm{SnAgCuFe}$
Mises strain of $\mathrm{SnAgCu}$ solder joints is higher than that of $\mathrm{SnAgCuFe}$ solder joints.

The strain of solder joints can be used to calculate the fatigue life based on the fatigue life model. The von Mises strain-von and Mises stress for the tenth cycle is shown in Fig.6, and the hysteresis loops of X-components of plastic strain and stress at the most critical locations of the solder joints are plotted in Fig.7. $\mathrm{SnAgCu}$ solder joints exhibit a larger amount of ratcheting than the $\mathrm{SnAgCuFe}$ solder joints. Strain ratcheting refers to the progressive increase in the mean strain in each successive cycle, which further proves the superiority of $\mathrm{SnAgCuFe}$ with smaller stress and strain.

\section{Fatigue Life Prediction}

For the fatigue life calculation of solder joints, the plastic strain range can be used to compute the fatigue life of $\mathrm{SnAgCuFe}, \mathrm{SnAgCu}$ and $\mathrm{SnPb}$ solder joints. The Engelmaier modified fatigue prediction equation can be written as Eq.(4).

$$
N_{\mathrm{f}}=\frac{1}{2}\left(\frac{\Delta \gamma}{2 \varepsilon_{\mathrm{f}}^{\prime}}\right)^{1 / c}
$$

where $N_{\mathrm{f}}$ is the fatigue life, $\Delta \gamma$ is the inelastic shear strain range per cycle calculated using finite element simulation, $\varepsilon_{\mathrm{f}}^{\prime}$ is the fatigue ductility coefficient which is taken as $2 \varepsilon_{\mathrm{f}}^{\prime}=0.514, c$ is the fatigue ductility exponent which is

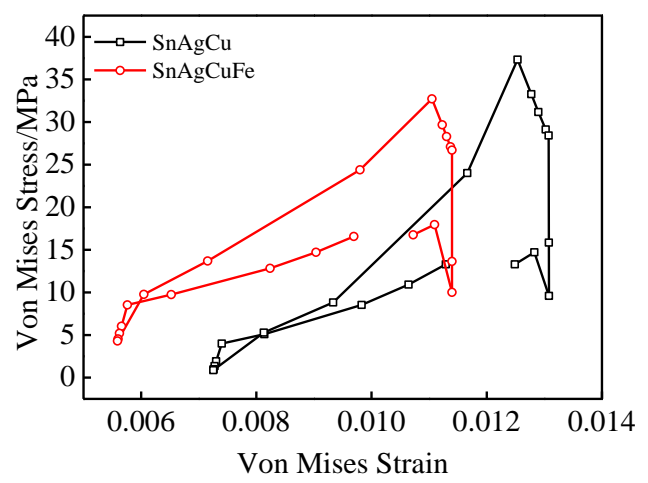

Fig.6 Von Mises stress-von Mises strain curve

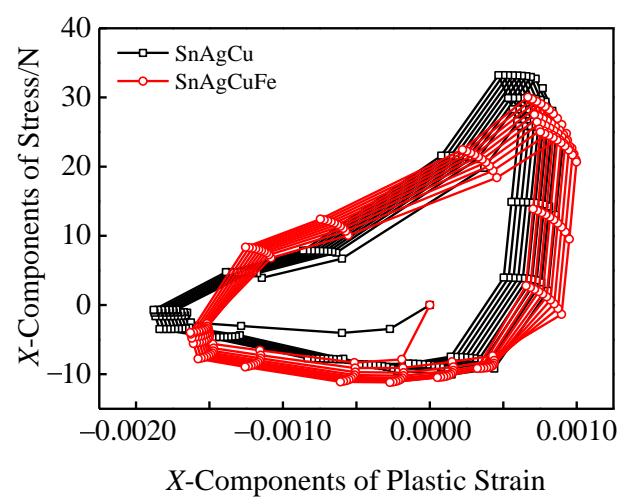

Fig.7 Stress-strain curves of $\mathrm{SnAgCu} / \mathrm{SnAgCuFe}$ 
approximately -0.5708 for $\mathrm{SnAgCu}$ base solder joints ${ }^{[19]}$.

The fatigue life of $\mathrm{SnAgCuFe}$ solder joints in WLCSP30 device is 2800 cycles, 2510 cycles for $\mathrm{SnAgCu}$ solder joints, and 2350 cycles for $\mathrm{SnPb}$ solder joints. The results show that the fatigue life of $\mathrm{SnAgCuFe}$ is $11.6 \%$ higher than that of $\mathrm{SnAgCu}$ solder joints, which demonstrate that the $\mathrm{Fe}$ addition can improve the reliability of $\mathrm{SnAgCu}$ solder joints, and can replace the traditional $\mathrm{SnPb}$ solder to be used in electronic industry.

\section{Conclusions}

1) The nine parameters of Anand constitutive model for $\mathrm{SnAgCuFe}$ solders are determined using tensile testing, and the model is used in the finite element simulation.

2) Based on finite element analysis, it is demonstrated that $\mathrm{SnAgCuFe}$ solder joints shows higher fatigue life than $\mathrm{SnAgCu}$ and $\mathrm{SnPb}$ solder joints.

\section{References}

1 Tay S L, Haseeb A S M A, Johan M R et al. Intermetallics[J], 2013, 33(33): 8

2 Zhang L, Han J G, Guo Y H et al. IEEE Transactions on Electron Devices[J], 2012, 59(12): 3269

3 Wang J X, Yin M, Lai Z M et al. Transactions of the China Welding Institution[J], 2011, 32(11): 69

4 Satyanarayan, Prabhu K N. Materials Science and Technology [J], 2013, 29(4): 464

5 Zhang L, Han J G, Guo Y H et al. Solar Energy Materials and Solar Cells[J], 2014, 130: 397
6 Zhang L, Han J G, Guo Y H et al. Materials Science and Engineering A[J], 2014, 597(5): 219

7 Kim K S, Huh S H, Suganuma K. Microelectronics Reliability [J], 2003, 43(2): 259

8 Liu Xiaoying, Ma Haitao, Luo Zhongbing et al. The Chinese Journal of Nonferrous Metals[J], 2012, 22(4): 1169 (in Chinese)

9 Wang Y W, Lin Y W, Tu C T et al. Journal of Alloys and Compounds[J], 2009, 478(1-2): 121

10 Zhang L, Fan X Y, Guo Y H et al. Electronic Materials Letters[J], 2014, 10(3): 645

11 Zhang L, Han J G, He C W et al. Journal of Materials Engineering[J], 2014(3): 55 (in Chinese)

12 Zhang L, Tu K N. Materials Science \& Engineering R[J], 2014, 82(1): 1

13 Kim J W, Jung S B. Materials Science and Engineering A[J], 2004, 371(1-2): 267

14 Zhang L, Xue S B, Gao L L et al. Modeling and Simulation in Materials Science and Engineering[J], 2009, 17(7): 075014

15 Zhang L, Chen X, Nose H et al. Journal of Mechanical Strength [J], 2004, 16(3): 339 (in Chinese)

16 Zhang L, Sun L, Guo Y H et al. Journal of Materials Science: Materials in Electronics[J], 2014, 25(3): 1209

17 Zhao J H, Gupta V, Lohia A et al. Journal of Electronic Packaging[J], 2010, 132(1): 011005

18 Zhang L, Xue S B, Lu F Y et al. China Welding[J], 2008, 17(2): 37

19 Zhang L, Han J G, Guo Y H et al. Microelectronic Reliability [J], 2014, 54(1): 281

\title{
WLCSP30 器件 SnAgCuFe 焊点可靠性研究
}

\author{
张 亮 $^{1,2}$, 郭永环 ${ }^{2}$, 孙 否 $^{1}$, 何成文 ${ }^{1}$ \\ (1. 江苏师范大学, 江苏 徐州 221116)
}

(2. 加州大学洛杉矶分校, 美国 洛杉矶 CA 90095)

\begin{abstract}
摘 要: 研究 SnAgCuFe 焊点的本构方程, 采用拉伸测试拟合本构模型的 9 个参数。基于有限元模拟应用 Anand 模型分析 WLCSP30 器 件 $\mathrm{SnAgCuFe}$ 焊点的应力-应变响应。结果表明, 器件最大应力集中在拐角焊点上表面, $\mathrm{SnAgCuFe}$ 焊点应力值明显小于 $\mathrm{SnAgCu}$ 焊点。基 于疲劳寿命预测模型, 证实微量的 $\mathrm{Fe}$ 可以显著提高 $\mathrm{SnAgCu}$ 焊点疲劳寿命, 因此 $\mathrm{SnAgCuFe}$ 可以替代传统的 $\mathrm{SnPb}$ 应用于电子封装。
\end{abstract}

关键词: Anand 模型; 焊点; 应力-应变; 疲劳寿命

作者简介: 张 亮, 男, 1984 年生, 博士, 教授, 江苏师范大学机电工程学院, 江苏 徐州 221116, 电话: 0516-83403320, E-mail: zhangliang@jsnu.edu.cn 